\title{
Advances using molecular data in insect systematics
}

Karl Kjer ${ }^{1}$, Marek Borowiec ${ }^{2}$, Paul Frandsen ${ }^{3}$, Jessica Ware ${ }^{1}$, Brian M. Wiegmann ${ }^{4 *}$ Fill in addresses

1 Rutgers University, Department of Biological Sciences, 415 Boyden Hall, Newark, NJ 07012, USA

2. University of Rochester, 226 Hutchison Hall, Rochester, NY 14627, USA 3 Smithsonian Institution, Office of Research Information Services, Office of the Chief Information Officer, Washington, D.C., USA 4 Department of Entomology \& Plant Pathology, North Carolina State University, Raleigh NC, 27695 USA

*Corresponding author

\section{Abstract}

The size of molecular datasets has been growing exponentially since the mid 1980s, and new technologies have now dramatically increased the slope of this increase. New datasets include genomes, transcriptomes, and hybrid capture data, producing hundreds or thousands of loci. With these datasets, we are approaching a consensus on the higher level insect phylogeny. Huge datasets can produce new challenges in interpreting branch support, and new opportunities in developing better models, and more sophisticated partitioning schemes. Dating analyses are improving as we recognize the importance of careful fossil calibration selection. With thousands of genes now available, coalescent methods have come of age. Barcode libraries continue to expand, and new methods are being developed for incorporating them into phylogenies with tens of thousands of individuals.

\section{Introduction}

While molecular data has revolutionized the higher level phylogeny of many taxa, the backbone phylogeny of insects was recovered quite accurately in 1904 [1] . Subsequent morphological treatments refined insect phylogeny, and corroborated many nodes [2] but differences among hypotheses had been difficult to resolve. The period from 1995-2010 was dominated by molecular studies from Sanger sequencing. Datasets typically ranged from 1,000 to 10,000 nucleotides and usually included nuclear rRNA, one or two mitochondrial genes, and sometimes one or two nuclear single copy genes. 
The seemingly revolutionary discoveries from this period have not been confirmed by much larger phylogenomic datasets [3]. Conflict was amplified by philosophical and analytical differences, recently reviewed [4]. At the dawn of the phylogenomic age, much controversy over higher-level insect phylogeny remained, and we awaited the age of "big data" to mediate our differences.

Datasets of extraordinary size are now common in phylogenetics, involving hundreds or thousands of genes. The size of datasets has been growing exponentially since the earliest studies in the 1980s (Fig. 1) and the recent works [3][5][6][7][8][9] are converging on consensus in higher level insect phylogeny (Fig. 2).

\section{Branch support and confidence}

Branch support measures such as bootstrap values and posterior probabilities provide confidence when a range of values are needed to distinguish signal from stochasticity. However, with very large datasets, stochasticity is effectively eliminated, and support values are often $100 \%$. Of course, this is not a bad thing. However, even small biases amplified by millions of nucleotides can result in strong support for erroneous results. Recognizing this, Misof et al. [3] examined model mis-specification [10] and used quartet mapping [11], which led them to question certain strongly supported relationships, most notably the monophyly of Palaeoptera and the placement of Psocodea as sister to Holometabola. Congruence among data sources can also be used for building confidence for a particular hypothesis. Although it is often stated that morphological data should simply be mapped onto molecular trees, we find this opinion to be too limiting, especially for insects, whose morphological characters are abundant, and still accumulating with advanced techniques such as micro computed tomography $(\mu \mathrm{CT})[12]$. Morphological data can provide corroboration and focus attention on problematic nodes. Corroboration can also come from embryological data [13] or from comparative studies of spermatozoa [14]. Despite its utility, congruence does not give us a quantitative or statistically meaningful value, and conflict from quartet mapping or the discovery of model mis-specification simply provides reason for skepticism. We are still looking for a more meaningful method of branch support for very large datasets.

\section{Data partitioning and model selection}

As phylogenetic datasets increase in size, the variation in the pattern of evolution among those data also increases. Two methods are often used for accounting for this increased variation: mixture models and partitioning. For large datasets, partitioning is the arguably the more popular method, though some studies have used mixture model methods on large datasets [15][16]. Partitioned models account for evolutionary variation by estimating independent model parameters for different subsets of sites within a concatenated alignment. In early model based molecular studies, the decision of how to partition the dataset was generally made a priori by the researcher based on some known biological feature of the data, e.g. gene boundaries, codon positions within a gene, or stems and loops of rRNA. The process of determining these boundaries is sometimes referred to as "more of an art than a science" [17]. More recently, algorithms have been proposed for the selection of partitioning schemes from pre- 
defined data blocks [18][19]. These heuristic algorithms join the pre-defined data blocks and accept joins based on whether they improve the score of an information theoretic metric such as AICC or BIC. For algorithms like these, the more data blocks pre-defined, a priori, the better (since subsequent improvements are made by joining data blocks). For example, Misof et al. [3] identified protein domains as their initial data blocks with the argument that the domain, not the gene, is the unit of selection, and showed that partitioning by domain outperformed partitioning by gene. Other methods have explored estimating partitioning schemes without a priori knowledge of partitioning boundaries and, instead, partition by clustering sites with similar site patterns or rates [20][21].

\section{Estimation of Divergence dates}

Historically, the timing of insect divergences was estimated using the fossil record, with palaeo-entomologists using stratiographic and radiometric information. With the advent of molecular phylogenies, branch lengths could be used to date the age of nodes in a phylogeny. However, a "molecular clock" is more of a hope than a reality. Thus fossil are used calibrate substitution rates in one part of the tree, which may then be extrapolated across the phylogeny to estimate divergence dates of taxa across the tree.

Unfortunately, the "clock" may tick at wildly different rates across lineages, and among genes which suggests the need for multiple calibration points, and some method to accommodate rate heterogeneity. In addition, fossil calibrations can be problematic, due to misapplication of stem and crown taxa, and ambiguously identified fossils [22][23]. Other factors such as gene choice, and modeling parameters can negatively influence molecular age estimates. Indeed, the dates produced by many of the earliest dating studies were considerably older than the palaeontological data suggested [24][25](Ware and Barden, this issue). The most recent insect node molecular ages were recovered by Misof et al. [3] and Tong et al. [26] differed in their fossil calibration choice, and the types of priors they used to model fossil calibrations, which resulted in significant age differences for some nodes [27]. Future divergence studies will benefit from a cooperative effort between paleontologists and entomologists, to ensure that fossil interpretation, calibration priors, and phylogenetic methods are rigorously implemented.

\section{Coalescence methods}

In the last 30 years, the fields of population genetics and systematics have become more fully synthesized. This is because sampling extant genetic variation has become the major source of evidence for understanding evolutionary processes, their effects on nucleotide evolution, and nucleotide-based estimation of phylogeny. Coalescent models incorporate population-level parameters and tree inference into a model of the estimated time to common ancestry (coalescence) for alleles in a population [28]. The method is particularly valuable for understanding the unique phylogenetic patterns revealed by different genes sampled among close relatives at the species level and below [29]. Because rates and the amount of available variation differ among genes, the 
pattern of population or species level relationships can differ for each gene. For this reason, it has been widely acknowledged that simple concatenation of genes into large datasets can obscure patterns of species diversification that are confounded by incomplete lineage sorting - a pattern of genetic variation with ancestral polymorphism retained through branching events [30][31][32]. Computationally powerful new methods have been developed that reconstruct phylogeny for each sampled gene individually using coalescent-based models, and these multispecies gene trees are summarized by various statistical consensus methods to evaluate support for the best supported topologies that spread the effects of lineage specific genetic biases more equitably in the analysis [33] [34] [35][36]. These methods are computationally challenging, but provide a powerful way to incorporate more aspects of the complex history that influenced extant genetic variation into the study. Multispecies coalescentbased methods have been applied in groundbreaking phylogeographic analyses various insect groups that have undergone rapid and relative recent species divergences [37][38][39][40][41]. These methods are also being extended to address deep divergences where rapid radiations may have been particularly prone to incomplete lineage sorting and the resulting phylogenetic pattern is difficult to resolve by more traditional methods [42][43][44].

\section{SNPs and population genetics}

Success in phylogenetics has always been tied to targeting the data to the question, which is linked to the range and depth of the question through time. SNPs, Single Nucleotide Polymorphisms, are variable sites that can be used to track relationships from alleles, to individual organisms, through populations and above the species level. SNPs are especially useful for revealing population structure and phylogeography [45]. However, the increasing availability of genomes, and the ease of sequencing and assembling partial genomes make it possible to map SNPS back to specific loci, establish homology through alignment, and to infer phylogeny. SNP datasets gathered for extensive genetic surveys of closely related species have been shown to have great power for resolving phylogenetic relationships [46][47][48].

\section{Barcodes}

Using "barcodes" to identify species has advanced over the past decade, and the

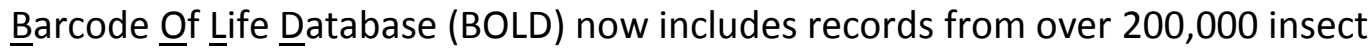
species. Compared with high-throughput sequencing, Sanger sequencing seems to be outdated and relatively expensive, when calculated at cost per nucleotide. However, when considering the combined cost of library preparation, tagging, and sequencing, if only a single locus is required, such as the barcode fragment, Sanger sequencing may still be a wise choice. Coissac et al. [49] discussed a strategy of augmenting standard barcode approaches with genomics. A reasonable phylogeny for a genus of Trichoptera was constructed by adding a single fragment of $28 \mathrm{~S}$ to the existing barcode data [48]. Zhou et al. [50] extended this idea by constructing backbone constraints from transcriptomes and then adding 16,000 unique barcode haplotypes from 40,000 individuals to fill out the leaves of the Trichoptera tree of life. Both examples explored 
the utility of maximizing the number of taxa in a phylogeny with a minimum amount of data, made possible by leveraging the enormous amount of available barcode data in combination with data from other sources. Recent efforts in barcoding have expanded to include high throughput sequences, and metabarcoding now routinely collects hundreds or potentially thousands of entire mitochondrial genomes from hundreds or potentially thousands of species. Initially, these studies [51][52][53][54] required PCR amplification, which can result in taxonomic biases based on differential amplification[54][55]. However, Zhou et al. [56] successfully applied a shotgun sequencing approach without PCR, and Liu et al. [57] dramatically enriched the relative yield of mitochondrial genomes with PCR-free approaches.

\section{Transcriptomes}

Initially, it was feared that transcriptomes would result in a haphazard matrix, filled with mostly missing data, as pioneering studies seemed to indicate. However, improvements in illumina sequencing technology, followed by matrix reduction with programs such as Aliscore [58], and MARE [59] resulted in data matrices that are largely complete. According to the OrthoDB database [60], there were a total of 1478 genes in common among all the arthropods in the Misof et al. [3] sample. All 1478 genes were recovered from most taxa, which means that genomes would not have provided more genes. Transcriptomes recover easy to model protein coding genes without introns, and do not require the processing, annotation, or data storage of genomes, making them ideal for phylogenetics.

\section{Target enrichment methods}

Targeted capture is an increasingly popular method that involves hybridization of custom-made molecular probes to loci of interest followed by sequencing of the captured sequences on a next-generation platform [61]. Two approaches utilizing this technique have become popular among phylogeneticists: Anchored Hybrid Enrichment (AHE; [62] and the so-called Ultraconserved Elements (UCEs; [63]). The main difference between AHE and UCEs is the nature of loci targeted, the former focusing on proteincoding genes and the latter utilizing any highly conserved regions that are flanked by more variable sequences. A large number of additional AHE projects with dense taxon sampling for Diptera, Hymenoptera, Lepidoptera, and Trichoptera are in progress, but yet unpublished. The first AHE analysis in flies resolved higher-level phylogeny of the flower flies, family Syrphidae [64]. UCEs have been applied to elucidate relationships among aculeate Hymenoptera [65] and within several groups of ants [66][67][68]. Low cost (as low as $\$ 40$ per sample), high data quality, and time-efficient sample preparation mean that target enrichment datasets are likely to range into thousands of taxa in the near future.

\section{Genomes: rare events}

As fully sequenced genomes become available, additional synapomorphic evidence can be inferred from rare genomic events, such as chromosomal duplications or rearrangements [69][70][71][72], changes in chromosome number or genome size [73] 
[74], and rearrangement or conservation in gene order or synteny relationships between organisms [75][76][77]. Large scale changes in genome architecture are increasingly considered to be important drivers of speciation itself [78] and are also leave signatures of hybridization and introgression [79]. Empirical data are only beginning to be available for larger phylogenetic comparisons, but genomic patterns are likely to be informative due to conservation and rarity once sampling is thorough enough to reveal the limits of their taxonomic distribution. A recent dramatic example comes from the analysis of 16 Anopheles mosquito genomes which revealed high rates of gene gain and loss and convincing evidence for significant interspecific hybridization leading to autosomal gene introgression among closely related malaria vectors [80]. Reconstruction of species phylogeny is obscured by hybridization, thus complicating the use of small numbers of genes to do so, but phylogenomics reveals the complexity of genetic, ecological, and behavioral factors that shape the history of species diversification and their impact on the genome.

\section{Phylogeography, diversification rate analysis, predicting future distributions}

Phylogenetic analyses of molecular data play a central role in testing evolutionary hypotheses, both at the population/species interface and at more ancient macroevolutionary timescales. Phylogeographic studies that track the history of closely related species in time and space are increasingly sophisticated in their use of multiple data sources and analytical approaches. A rich conceptual and analytical framework is flourishing that combines genetic, population, and species level data to connect evolutionary patterns through estimates of gene flow, migration, and historical changes in geographic range [30]. These powerful tools are used in tracking invasive species [81][82][83], delimiting hybrid zones and speciation events [84], revealing cryptic species [85], and documenting the influence of selective sweeps and habitat degradation [86][87] --to name just a few of many applications. Macroevolutionary methods that capitalize on computing power and the availability of phylogenetic trees have also made it possible to evaluate changes in diversification rate through time [88][89][90]. These methods look for evidence of significant changes in the number of new lineages originating through time, or track the possible slow downs in lineage accumulation due to periods of greater than expected rates of extinction. Diversification rate tests have been applied at deep levels among insect orders [91] [92] and below [93] [94], but are most powerful in their application to fully sampled studies evaluating the diversification of rapidly radiating species in diverse clades [95][91][96]. Diversification rate studies provide insight 'key adaptation' hypotheses such as powered flight, complete metamorphosis, or phytophagy as causes for the rapid increases in species diversity that are a repeated and compelling feature of the history of insects [97][92][98]. Phylogenetic trees provide important temporal context connecting organisms and their changing environments. Phylogenies are a key parameter in studies that evaluate current biogeographic distributions, link taxa to their historic distribution and areas of endemism, and organize the specificity of their ecological requirements [99][100]. Phylogenetic assessment thus plays a key role in evaluating the affects of climate change and habitat loss for insects [101][102]. Ultimately, molecular systematic 
data and their broad application are relevant not only as a historical record of phylogeny, but provide the framework for understanding ecological and evolutionary patterns, contextualizing changes in biotic interactions and community-level processes, and for predicting and evaluating the impact of these changes on insect biodiversity.

\section{Acknowledgements:}

MB would like to thank Bonnie Blaimer and Michael Branstetter for providing data set size information. This contribution was partially supported by grants from the US National Science Foundation, DEB-1328784 and DEB-1542395 to BMW.

\section{Figure Captions:}

Fig. 1. Size of phylogenetic datasets through time. $X$ axis; Dates of publication of selected phylogenetic works. $Y$ axis; number of sites multiplied by the number of taxa. For transcriptome datasets this number was then multiplied by (1 minus the percent missing data). "Ribosomal RNA" points frequently included other data. W09=; M10=[6]; $\mathrm{N} 12=[77] ; \mathrm{J} 13=[42] ; \mathrm{S} 13=[7] ; \mathrm{L} 13=[8] ; \mathrm{P} 14=[9] \mathrm{M} 14=[3] ; \mathrm{B} 15=[66] ; \mathrm{B} 16=[68] ; \mathrm{Z16}=[50]$. Others are as in Kjer et al. [4], Fig 5B.

Fig. 2. Consensus phylogeny from Misof et al. [3] . Collapsed nodes at Palaeoptera and Acercaria are discussed in the supplementary materials of that paper.

\section{References:}

1. Börner C: Zur Systematik der Hexapoda. Zool Anz 1904, 27:511-533.

2. Friedrich F, Matsumura Y, Pohl H, Bai M, Hörnschemeyer T, Beutel RG: Insect morphology in the age of phylogenomics: innovative techniques and its future role in systematics. Entomol. Sci. 2014, 17:1-24.

3. Misof B, Liu S, Meusemann K, Peters RS, Donath A, Mayer C, Frandsen PB, Ware J, Flouri T, Beutel RG, et al.: Phylogenomics resolves the timing and pattern of insect evolution. Science 2014, 346:763-767. A current estimate of insect order level phylogeny comprising the largest dataset for insect phylogenetics to date (fig. 2), from 1478 loci.

4. Kjer KM, Simon C, Yavorskaya M, Beutel RG: Progress, pitfalls, and parallel universes: A history of insect phylogenetics. J. R. Soc. Interface 2016, 13 : 20160363. A recent detailed review of the history of the field, with many key references.

5. Wiegmann BM, Trautwein MD, Kim J-W, Cassel BK, Bertone MA, Winterton SL, Yeates DK: Single-copy nuclear genes resolve the phylogeny of the holometabolous insects. BMC Biol. 2009, 7:34. 
6. McKenna DD, Farrell BD: 9-Genes Reinforce the Phylogeny of Holometabola and Yield Alternate Views on the Phylogenetic Placement of Strepsiptera. PLOS ONE 2010, 5:e11887.

7. Simon S, Narechania A, DeSalle R, Hadrys H: Insect Phylogenomics: Exploring the Source of Incongruence Using New Transcriptomic Data. Genome Biol. Evol. 2012, 4:1295-1309.

8. Letsch H, Simon S: Insect phylogenomics: new insights on the relationships of lower neopteran orders (Polyneoptera). Syst. Entomol. 2013, 38:783793.

9. Peters RS, Meusemann K, Petersen M, Mayer C, Wilbrandt J, Ziesmann T, Donath A, Kjer KM, Aspöck U, Aspöck H, et al.: The evolutionary history of holometabolous insects inferred from transcriptome-based phylogeny and comprehensive morphological data. BMC Evol. Biol. 2014, 14:52.

10. Dell'Ampio E, Meusemann K, Szucsich NU, Peters RS, Meyer B, Borner J, Petersen M, Aberer AJ, Stamatakis A, Walzl MG, et al.: Decisive Data Sets in Phylogenomics: Lessons from Studies on the Phylogenetic Relationships of Primarily Wingless Insects. Mol. Biol. Evol. 2014, 31:239-249.

11. Strimmer K, von Haeseler A: Likelihood-mapping: a simple method to visualize phylogenetic content of a sequence alignment. Proc. Natl. Acad. Sci. U. S. A. 1997, 94:6815-6819.

12. Beutel RG, Kristensen NP: Morphology and insect systematics in the era of phylogenomics. Arthropod Struct. Dev. 2012, 41:303-305.

13. Mashimo Y, Beutel RG, Dallai R, Lee C-Y, Machida R: Embryonic development of Zoraptera with special reference to external morphology, and its phylogenetic implications (Insecta). J. Morphol. 2014, 275:295-312.

14. Dallai R, Gottardo M, Beutel RG: Structure and Evolution of Insect Sperm: New Interpretations in the Age of Phylogenomics. Annu. Rev. Entomol. 2016, 61:1-23.

15. Borowiec ML, Lee EK, Chiu JC, Plachetzki DC: Extracting phylogenetic signal and accounting for bias in whole-genome data sets supports the Ctenophora as sister to remaining Metazoa. BMC Genomics 2015, 16:987.

16. Pisani D, Pett W, Dohrmann M, Feuda R, Rota-Stabelli O, Philippe H, Lartillot N, Wörheide G: Genomic data do not support comb jellies as the sister group to all other animals. Proc. Natl. Acad. Sci. 2015, 112:15402-15407.

17. Yang Z, Rannala B: Molecular phylogenetics: principles and practice. Nat. Rev. Genet. 2012, 13:303-314. 
18. Li C, Lu G, Ortí G: Optimal Data Partitioning and a Test Case for Ray-Finned Fishes (Actinopterygii) Based on Ten Nuclear Loci. Syst. Biol. 2008, 57:519539.

19. Lanfear R, Calcott B, Ho SYW, Guindon S: PartitionFinder: combined selection of partitioning schemes and substitution models for phylogenetic analyses. Mol. Biol. Evol. 2012, doi:10.1093/molbev/mss020. An important advance in guiding model specification within molecular phylogenetic datasets. After partitioning the data into a-priori subsets, the PartitionFinder program lumps subsets together that are estimated to be evolving under a similar model.

20. Kjer KM, Honeycutt RL: Site specific rates of mitochondrial genomes and the phylogeny of eutheria. BMC Evol. Biol. 2007, 7:8.

21. Frandsen PB, Calcott B, Mayer C, Lanfear R: Automatic selection of partitioning schemes for phylogenetic analyses using iterative k-means clustering of site rates. BMC Evol. Biol. 2015, 15:13.

22. Parham JF, Donoghue PCJ, Bell CJ, Calway TD, Head JJ, Holroyd PA, Inoue JG, Irmis RB, Joyce WG, Ksepka DT, et al.: Best Practices for Justifying Fossil Calibrations. Syst. Biol. 2012, 61:346-359. The selection of fossil calibration points can have a large impact on the results from dating analysis. This paper describes repeatable and conservative principles that should be used as "best practices" in order to select appropriate fossils for divergence dating.

23. Ksepka DT, Parham JF, Allman JF, Benton MJ, Carrano MT, Cranston KA, Donoghue PCJ, Head JJ, Hermsen EJ, Irmis RB, et al.: The Fossil Calibration Database-A New Resource for Divergence Dating. Syst. Biol. 2015, 64:853859.

24. Thomas JA, Ware JL: Molecular and Fossil Dating: A Compatible Match? Entomol. Am. 2011, 117:1-8.

25. Ksepka DT, Benton MJ, Carrano MT, Gandolfo MA, Head JJ, Hermsen EJ, Joyce WG, Lamm KS, Patané JSL, Phillips MJ, et al.: Synthesizing and databasing fossil calibrations: divergence dating and beyond. Biol. Lett. 2011, 7:801803.

26. Tong KJ, Duchêne S, Ho SYW, Lo N: Insect phylogenomics. Comment on "Phylogenomics resolves the timing and pattern of insect evolution." Science 2015, 349:487.

27. Kjer KM, Ware JL, Rust J, Wappler T, Lanfear R, Jermiin LS, Zhou X, Aspöck H, Aspöck U, Beutel RG, et al.: Insect phylogenomics. Response to Comment on "Phylogenomics resolves the timing and pattern of insect evolution." Science 2015, 349:487. 
28. Tavare S, Balding DJ, Griffiths RC, Donnelly P: Inferring Coalescence Times from DNA Sequence Data. Genetics 1997, 145:505-518.

29. Knowles LL: Statistical Phylogeography. Annu. Rev. Ecol. Evol. Syst. 2009, 40:593-612.

30. Edwards SV, Liu L, Pearl DK: High-resolution species trees without concatenation. Proc. Natl. Acad. Sci. 2007, 104:5936-5941.

31. Edwards SV, Xi Z, Janke A, Faircloth BC, McCormack JE, Glenn TC, Zhong B, Wu S, Lemmon EM, Lemmon AR, et al.: Implementing and testing the multispecies coalescent model: A valuable paradigm for phylogenomics. Mol. Phylogenet. Evol. 2016, 94, Part A:447-462.

32. Degnan JH, Rosenberg NA: Gene tree discordance, phylogenetic inference and the multispecies coalescent. Trends Ecol. Evol. 2009, 24:332-340.

33. McVay JD, Carstens BC: Phylogenetic Model Choice: Justifying a Species Tree or Concatenation Analysis. J. Phylogenetics Evol. Biol. 2013, 1:114. doi: 10.4172/2329-9002.1000114

34. Mirarab S, Reaz R, Bayzid MS, Zimmermann T, Swenson MS, Warnow T: ASTRAL: genome-scale coalescent-based species tree estimation. Bioinformatics 2014, 30:i541-i548.

35. Mirarab S, Bayzid MS, Warnow T: Evaluating Summary Methods for Multilocus Species Tree Estimation in the Presence of Incomplete Lineage Sorting. Syst. Biol. 2016, 65:366-380.

36. Ogilvie HA, Heled J, Xie D, Drummond AJ: Performance and statistical accuracy of *BEAST and comparisons with other methods. Syst. Biol. 2016, 65:381-396.

37. Marske KA, Leschen RAB, Buckley TR: Concerted Versus Independent Evolution and the Search for Multiple Refugia: Comparative Phylogeography of Four Forest Beetles. Evolution 2012, 66:1862-1877.

38. Knowles LL, Klimov PB: Estimating phylogenetic relationships despite discordant gene trees across loci: the species tree of a diverse species group of feather mites (Acari: Proctophyllodidae). Parasitology 2011, 138:1750-1759.

39. Cuthill JH, Charleston M: Phylogenetic Codivergence Supports Coevolution of Mimetic Heliconius Butterflies. PLOS ONE 2012, 7:e36464.

40. Talavera G, Lukhtanov VA, Rieppel L, Pierce NE, Vila R: In the shadow of phylogenetic uncertainty: the recent diversification of Lysandra 
butterflies through chromosomal change. Mol. Phylogenet. Evol. 2013, 69:469-478.

41. Wang Y, Zhou X, Yang D, Rokas A: A Genome-Scale Investigation of Incongruence in Culicidae Mosquitoes. Genome Biol. Evol. 2015, 7:34633471 .

42. Johnson BR, Borowiec ML, Chiu JC, Lee EK, Atallah J, Ward PS: Phylogenomics resolves evolutionary relationships among ants, bees, and wasps. Curr. Biol. 2013, 23:2058-62.

43. Fernández R, Edgecombe GD, Giribet G: Exploring phylogenetic Relationships within Myriapoda and the Effects of Matrix Composition and Occupancy on Phylogenomic Reconstruction. Syst. Biol. 2016, doi:10.1093/sysbio/syw041.

44. Lanier HC, Knowles LL: Applying species-tree analyses to deep phylogenetic histories: Challenges and potential suggested from a survey of empirical phylogenetic studies. Mol. Phylogenet. Evol. 2015, 83:191-199.

45. Brito PH, Edwards SV: Multilocus phylogeography and phylogenetics using sequence-based markers. Genetica 2009, 135:439-455.

46. Darwell CT, Rivers DM, Althoff DM: RAD-seq phylogenomics recovers a wellresolved phylogeny of a rapid radiation of mutualistic and antagonistic yucca moths. Syst. Entomol. 2016, 41:672-682.

47. Ebel ER, DaCosta JM, Sorenson MD, Hill RI, Briscoe AD, Willmott KR, Mullen SP: Rapid diversification associated with ecological specialization in Neotropical Adelpha butterflies. Mol. Ecol. 2015, 24:2392-2405.

48. Kjer KM, Zhou X, Frandsen PB, Thomas JA, Blahnik RJ: Moving toward specieslevel phylogeny using ribosomal DNA and COI barcodes: An example from the diverse caddisfly genus Chimarra (Trichoptera: Philopotamidae). ResearchGate 2014, 72:345-354.

49. Coissac E, Hollingsworth PM, Lavergne S, Taberlet P: From barcodes to genomes: extending the concept of DNA barcoding. Mol. Ecol. 2016, 25:1423-1428.

50. Zhou X, Frandsen PB, Holzenthal RW, Beet CR, Bennett KR, Blahnik RJ, Bonada N, Cartwright D, Chuluunbat $\mathrm{S}$, Cocks GV, et al.: The Trichoptera barcode initiative: a strategy for generating a species-level Tree of Life. Phil Trans $R$ Soc B 2016, 371:20160025. 
51. Hajibabaei M, Shokralla S, Zhou X, Singer GAC, Baird DJ: Environmental Barcoding: A Next-Generation Sequencing Approach for Biomonitoring Applications Using River Benthos. PLOS ONE 2011, 6:e17497.

52. Yu DW, Ji Y, Emerson BC, Wang X, Ye C, Yang C, Ding Z: Biodiversity soup: metabarcoding of arthropods for rapid biodiversity assessment and biomonitoring. Methods Ecol. Evol. 2012, 3:613-623.

53. Baird DJ, Hajibabaei M: Biomonitoring 2.0: a new paradigm in ecosystem assessment made possible by next-generation DNA sequencing. Mol. Ecol. 2012, 21:2039-2044.

54. Liu S, Li Y, Lu J, Su X, Tang M, Zhang R, Zhou L, Zhou C, Yang Q, Ji Y, et al.: SOAPBarcode: revealing arthropod biodiversity through assembly of Illumina shotgun sequences of PCR amplicons. Methods Ecol. Evol. 2013, 4:1142-1150.

55. Taberlet P, Coissac E, Pompanon F, Brochmann C, Willerslev E: Towards nextgeneration biodiversity assessment using DNA metabarcoding. Mol. Ecol. 2012, 21:2045-2050.

56. Zhou X, Li Y, Liu S, Yang Q, Su X, Zhou L, Tang M, Fu R, Li J, Huang Q: Ultra-deep sequencing enables high-fidelity recovery of biodiversity for bulk arthropod samples without PCR amplification. Gigascience 2013, 2:1.

57. Liu S, Wang X, Xie L, Tan M, Li Z, Su X, Zhang H, Misof B, Kjer KM, Tang M, et al.: Mitochondrial capture enriches mito-DNA 100 fold, enabling PCR-free mitogenomics biodiversity analysis. Mol. Ecol. Resour. 2016, 16:470-479. A high throughput metabarcoding effort that increases the relative proportion of mitochondrial genomes without PCR bias.

58. Misof B, Misof K: A Monte Carlo Approach Successfully Identifies Randomness in Multiple Sequence Alignments : A More Objective Means of Data Exclusion. Syst. Biol. 2009, 58:21-34.

59. Meyer B, Misof B: MARE v0.1-rc. 2010.

60. Kriventseva EV, Tegenfeldt F, Petty TJ, Waterhouse RM, Simão FA, Pozdnyakov IA, Ioannidis P, Zdobnov EM: OrthoDB v8: update of the hierarchical catalog of orthologs and the underlying free software. Nucleic Acids Res. 2015, 43:D250-256.

61. Gnirke A, Melnikov A, Maguire J, Rogov P, LeProust EM, Brockman W, Fennell T, Giannoukos G, Fisher S, Russ C, et al.: Solution hybrid selection with ultralong oligonucleotides for massively parallel targeted sequencing. Nat. Biotechnol. 2009, 27:182-189. 
62. Lemmon AR, Emme SA, Lemmon EM: Anchored hybrid enrichment for massively high-throughput phylogenomics. Syst. Biol. 2012, 61:727-744. A method for generating hundreds of specific targeted loci for high throughput sequencing. Probes are designed from orthologous exons identified in transcriptomes or genomes among closely related taxa.

63. Faircloth BC, McCormack JE, Crawford NG, Harvey MG, Brumfield RT, Glenn TC: Ultraconserved elements anchor thousands of genetic markers spanning multiple evolutionary timescales. Syst. Biol. 2012, 61:717-726. A method for generating hundreds of targeted loci for high throughput sequencing, in which probes are designed from highly conserved regions of the genome.

64. Young AD, Lemmon AR, Skevington JH, Mengual X, Ståhls G, Reemer M, Jordaens K, Kelso S, Lemmon EM, Hauser M, et al.: Anchored enrichment dataset for true flies (order Diptera) reveals insights into the phylogeny of flower flies (family Syrphidae). BMC Evol. Biol. 2016, 16:143.

65. Faircloth BC, Branstetter MG, White ND, Brady SG: Target enrichment of ultraconserved elements from arthropods provides a genomic perspective on relationships among Hymenoptera. Mol. Ecol. Resour. 2015, 15:489-501.

66. Blaimer BB, Brady SG, Schultz TR, Lloyd MW, Fisher BL, Ward PS:

Phylogenomic methods outperform traditional multi-locus approaches in resolving deep evolutionary history: a case study of formicine ants. $B M C$ Evol. Biol. 2015, 15:271. DOI: 10.1186/s12862-015-0552-5

67. Blaimer BB, LaPolla JS, Branstetter MG, Lloyd MW, Brady SG: Phylogenomics, biogeography and diversification of obligate mealybug-tending ants in the genus Acropyga. Mol. Phylogenet. Evol. 2016, 102:20-29.

68. Branstetter MG, Longino JT, Reyes-López J, Schultz TR, Brady SG: Into the tropics: phylogenomics and evolutionary dynamics of a contrarian clade of ants. bioRxiv 2016, doi: http://dx.doi.org/10.1101/039966

69. Lukhtanov VA, Kuznetsova VG: What genes and chromosomes say about the origin and evolution of insects and other arthropods. Russ. J. Genet. 2010, 46:1115-1121.

70. Rokas null, Holland null: Rare genomic changes as a tool for phylogenetics. Trends Ecol. Evol. 2000, 15:454-459.

71. Talavera G, Lukhtanov VA, Rieppel L, Pierce NE, Vila R: In the shadow of phylogenetic uncertainty: The recent diversification of Lysandra 
butterflies through chromosomal change. Mol. Phylogenet. Evol. 2013, 69:469-478.

72. Van de Peer Y, Maere S, Meyer A: The evolutionary significance of ancient genome duplications. Nat. Rev. Genet. 2009, 10:725-732.

73. Blackmon H, Ross L, Bachtrog D: Sex Determination, Sex Chromosomes, and Karyotype Evolution in Insects. J. Hered. 2016, doi:10.1093/jhered/esw047.

74. Ardila-Garcia AM, Umphrey GJ, Gregory TR: An expansion of the genome size dataset for the insect order Hymenoptera, with a first test of parasitism and eusociality as possible constraints. Insect Mol. Biol. 2010, 19:337-346.

75. Bagadia M, Singh A, Singh Sandhu K: Three Dimensional Organization of Genome Might Have Guided the Dynamics of Gene Order Evolution in Eukaryotes. Genome Biol. Evol. 2016, 8:946-954.

76. Li J, Waterhouse RM, Zdobnov EM: A remarkably stable TipE gene cluster: evolution of insect Para sodium channel auxiliary subunits. BMC Evol. Biol. 2011, 11:337.

77. Niehuis O, Hartig G, Grath S, Pohl H, Lehmann J, Tafer H, Donath A, Krauss V, Eisenhardt $C$, Hertel J, et al.: Genomic and morphological evidence converge to resolve the enigma of Strepsiptera. Curr. Biol. CB 2012, 22:1309-1313. An early analysis of entire genomes, addressing the phylogenetic position of Strepsiptera.

78. Flaxman SM, Wacholder AC, Feder JL, Nosil P: Theoretical models of the influence of genomic architecture on the dynamics of speciation. Mol. Ecol. 2014, 23:4074-4088.

79. Payseur BA, Rieseberg LH: A genomic perspective on hybridization and speciation. Mol. Ecol. 2016, 25:2337-2360.

80. Fontaine MC, Pease JB, Steele A, Waterhouse RM, Neafsey DE, Sharakhov IV, Jiang X, Hall AB, Catteruccia F, Kakani E, et al.: Extensive introgression in a malaria vector species complex revealed by phylogenomics. Science 2015, 347:1258524.

81. Gotzek D, Brady SG, Kallal RJ, LaPolla JS: The Importance of Using Multiple Approaches for Identifying Emerging Invasive Species: The Case of the Rasberry Crazy Ant in the United States. PLOS ONE 2012, 7:e45314.

82. Le Roux J j., Rubinoff D: Molecular data reveals California as the potential source of an invasive leafhopper species, Macrosteles sp. nr. severini, transmitting the aster yellows phytoplasma in Hawaii. Ann. Appl. Biol. 2009, 154:419-427. 
83. Porretta D, Mastrantonio V, Bellini R, Somboon P, Urbanelli S: Glacial History of a Modern Invader: Phylogeography and Species Distribution Modelling of the Asian Tiger Mosquito Aedes albopictus. PLOS ONE 2012, 7:e44515.

84. Nadeau NJ, Ruiz M, Salazar P, Counterman B, Medina JA, Ortiz-Zuazaga H, Morrison A, McMillan WO, Jiggins CD, Papa R: Population genomics of parallel hybrid zones in the mimetic butterflies, $H$. melpomene and $H$. erato. Genome Res. 2014, 24:1316-1333.

85. Condon MA, Scheffer SJ, Lewis ML, Swensen SM: Hidden Neotropical Diversity: Greater Than the Sum of Its Parts. Science 2008, 320:928-931.

86. Morgan K, O'Loughlin SM, Chen B, Linton Y-M, Thongwat D, Somboon P, Fong MY, Butlin R, Verity R, Prakash A, et al.: Comparative phylogeography reveals a shared impact of pleistocene environmental change in shaping genetic diversity within nine Anopheles mosquito species across the IndoBurma biodiversity hotspot. Mol. Ecol. 2011, 20:4533-4549.

87. Raychoudhury R, Grillenberger BK, Gadau J, Bijlsma R, van de Zande L, Werren $\mathrm{JH}$, Beukeboom LW: Phylogeography of Nasonia vitripennis (Hymenoptera) indicates a mitochondrial-Wolbachia sweep in North America. Heredity 2010, 104:318-326.

88. Alfaro ME, Santini F, Brock C, Alamillo H, Dornburg A, Rabosky DL, Carnevale G, Harmon LJ: Nine exceptional radiations plus high turnover explain species diversity in jawed vertebrates. Proc. Natl. Acad. Sci. 2009, 106:13410-13414.

89. Rabosky DL: Automatic Detection of Key Innovations, Rate Shifts, and Diversity-Dependence on Phylogenetic Trees. PLOS ONE 2014, 9:e89543.

90. Ng J, Smith SD: How traits shape trees: new approaches for detecting character state-dependent lineage diversification. J. Evol. Biol. 2014, 27:2035-2045.

91. Condamine FL, Toussaint EFA, Cotton AM, Genson GS, Sperling FAH, Kergoat GJ: Fine-scale biogeographical and temporal diversification processes of peacock swallowtails (Papilio subgenus Achillides) in the Indo-Australian Archipelago. Cladistics 2013, 29:88-111.

92. Rainford JL, Hofreiter M, Nicholson DB, Mayhew PJ: Phylogenetic Distribution of Extant Richness Suggests Metamorphosis Is a Key Innovation Driving Diversification in Insects. PLOS ONE 2014, 9:e109085.

93. Wiegmann BM, Trautwein MD, Winkler IS, Barr NB, Kim J-W, Lambkin C, Bertone MA, Cassel BK, Bayless KM, Heimberg AM, et al.: Episodic radiations in the fly tree of life. Proc. Natl. Acad. Sci. 2011, 108:5690-5695. 
94. Mckenna DD, Wild AL, Kanda K, Bellamy CL, Beutel RG, Caterino MS, Farnum CW, Hawks DC, Ivie MA, Jameson ML, et al.: The beetle tree of life reveals that Coleoptera survived end-Permian mass extinction to diversify during the Cretaceous terrestrial revolution. Syst. Entomol. 2015, 40:835-880.

95. Winkler IS, Mitter C, Scheffer SJ: Repeated climate-linked host shifts have promoted diversification in a temperate clade of leaf-mining flies. Proc. Natl. Acad. Sci. 2009, 106:18103-18108.

96. Rodriguez J, Pitts JP, Florez JA, Bond JE, von Dohlen CD: Molecular phylogeny of Pompilinae (Hymenoptera: Pompilidae): Evidence for rapid diversification and host shifts in spider wasps. Mol. Phylogenet. Evol. 2016, 94:55-64.

97. Mitter C, Farrell B, Wiegmann B: The Phylogenetic Study of Adaptive Zones: Has Phytophagy Promoted Insect Diversification? Am. Nat. 1988, 132:107128.

98. Wiens JJ, Lapoint RT, Whiteman NK: Herbivory increases diversification across insect clades. Nat. Commun. 2015, 6:8370.

99. Fordham DA, Brook BW, Moritz C, Nogués-Bravo D: Better forecasts of range dynamics using genetic data. Trends Ecol. Evol. 2014, 29:436-443.

100. Fritz SA, Schnitzler J, Eronen JT, Hof C, Böhning-Gaese K, Graham CH: Diversity in time and space: wanted dead and alive. Trends Ecol. Evol. 2013, 28:509516.

101. Pauls SU, Nowak C, Bálint M, Pfenninger M: The impact of global climate change on genetic diversity within populations and species. Mol. Ecol. 2013, 22:925-946.

102. Taubmann J, Theissinger K, Feldheim KA, Laube I, Graf W, Haase P, Johannesen $\mathrm{J}, \mathrm{Pauls}$ SU: Modelling range shifts and assessing genetic diversity distribution of the montane aquatic mayfly Ameletus inopinatus in Europe under climate change scenarios. Conserv. Genet. 2010, 12:503-515. 
$\checkmark$ Morphology

- Mitochondrial and nuclear genes (not rRNA)

O Ribosomal RNA

$\square$ Genomes or Transcriptomes

10000000

1000000

100000

P14 $\square$

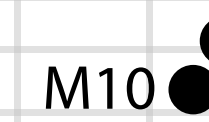

0 
Figure2 Ellipura

-O HEXAPODA

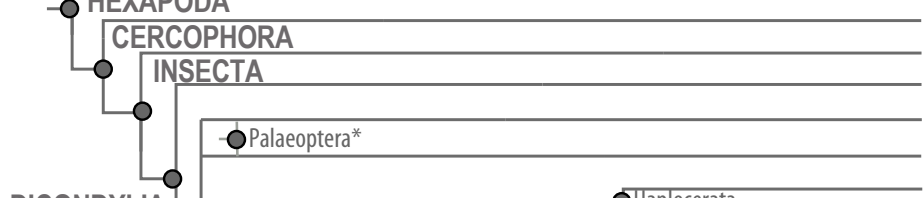

DICONDYLIA

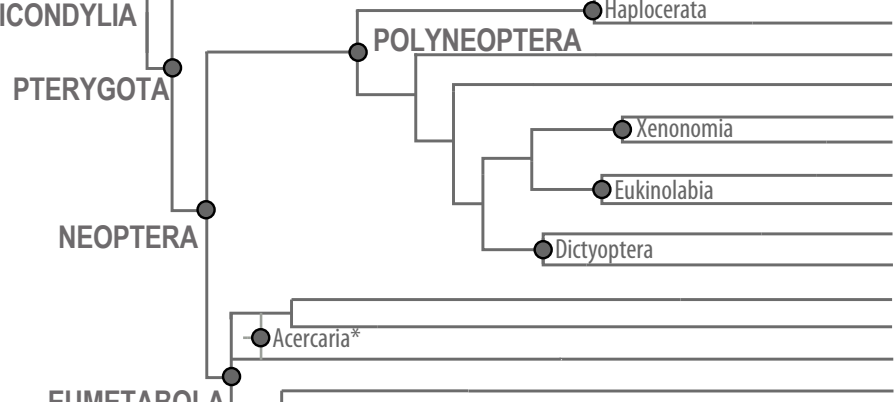

EUMETABOLA

HOLOMETABOLA

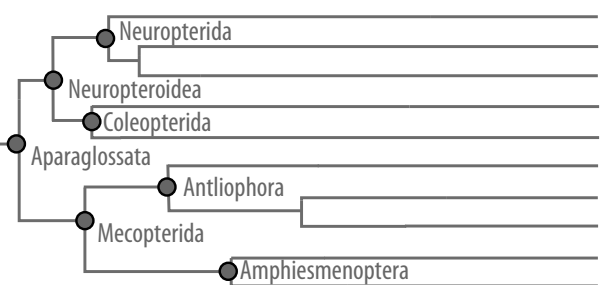

COLLEMBOLA

PROTURA

DIPLURA

ARCHAEOGNATHA ZYGENTOMA

ODONATA

EPHEMEROPTERA

ZORAPTERA

DERMAPTERA

PLECOPTERA

ORTHOPTERA

MANTOPHASMATODEA GRYLLOBLATTODEA

EMBIOPTERA

PHASMATODEA

MANTODEA

BLATTODEA

THYSANOPTERA

HEMIPTERA

PSOCODEA

HYMENOPTERA

RAPHIDIOPTERA

MEGALOPTERA

NEUROPTERA

COLEOPTERA

STREPSIPTERA

DIPTERA

SIPHONAPTERA

MECOPTERA

TRICHOPTERA LEPIDOPTERA 